Disponível em:

http://editora.unoesc.edu.br/index.php/race

RACE, Joaçaba, v. 17, n. 2, p. 667-694, maio/ago. 2018

\title{
RETORNO DOS INVESTIMENTOS DE EMPRESAS DO AGRONEGÓCIO BRASILEIRO
}

\author{
Return of investments of brazilian agribusiness companies
}

Cristian Baú Dal Magro

E-mail: cristianbaumagro@gmail.com

Doutor em Ciências Contábeis e Administração pela Universidade Regional de Blumenau; Mestre em Ciências Contábeis pela Universidade Regional de Blumenau; Professor no Programa de Pós-graduação em Ciências Contábeis e Administração da Universidade Comunitária da Região de Chapecó. Endereço para contato: Servidão Anjo da Guarda, 295-D - Efapi, 89809-900, Chapecó, Santa Catarina, Brasil.

Edgar Pamplona

E-mail: edgarpamplona@hotmail.com

Mestre em Ciências Contábeis pela Universidade Regional de Blumenau; Doutorando em Ciências Contábeis e Administração na Universidade Regional de Blumenau;

Bolsista Capes no Programa de Pós-graduação em Ciências Contábeis da Universidade Regional de Blumenau.

Marcello Christiano Gorla

E-mail: gorlacontabil@yahoo.com.br

Doutor em Ciências Contábeis e Administração pela Universidade Regional de Blumenau; Mestre em Ciências Contábeis pela Universidade Regional de Blumenau; Pós-doutorando no Programa de Pós-graduação em Contabilidade da Universidade Federal de Santa Catarina.

Tarcísio Pedro da Silva

E-mail: tarcisio@furb.br

Doutor em Ciências Contábeis e Administração pela Universidade Regional de Blumenau; Mestre em Ciências Contábeis pela Universidade Regional de Blumenau; Professor no Programa de Pós-graduação em Ciências Contábeis da Universidade

Regional de Blumenau. 
Artigo recebido em 26 de dezembro de 2017. Aceito em 12 de julho de 2018.

Resumo

O objetivo com o estudo foi verificar a atratividade nos retornos dos investimentos de empresas brasileiras do agronegócio com o uso do modelo Capital Asset Pricing Model (CAPM). Para isso, realizou-se pesquisa descritiva, análise documental e utilizou-se abordagem quantitativa. A amostra é composta por ações de 13 empresas do agronegócio brasileiro negociadas na BM\&FBovespa e o período de análise compreende os anos de 2010 a 2014. Os achados apontaram que o $C A P M$ identifica maior atratividade para as empresas do agronegócio brasileiro quando comparado com a média do mercado dado pelo IBovespa. Contudo, o CAPM foi eficiente para dimensionar os retornos esperados apenas nos anos 2010, 2011 e 2014, sendo que, em 2012 e 2013, a atratividade apontada pelo CAPM foi significativamente menor do que o retorno real, fato que pode ser entendido por meio de aspectos econômicos, pois o setor do agronegócio cresceu nesse período em oposição ao baixo desempenho geral do mercado. Por fim, salientase que o retorno real médio foi constatado superior para as empresas do agronegócio brasileiro em relação ao retorno do mercado em geral. Por vezes, apresentaram retornos reais maiores do que o esperado e, assim, foram consideradas atrativas para investimentos pela maximização dos ganhos no mercado acionário brasileiro.

Palavras-chave: Atratividade dos investimentos. CAPM. Empresas do agronegócio.

\section{Abstract}

The aim of the study is to assess the attractiveness of the investment returns of Brazilian agribusiness companies using the Capital Asset Pricing Model (CAPM). For this, was achieved descriptive research, document analysis and quantitative approach. The sample is composed of 13 Brazilian agribusiness companies listed on the BM\&FBovespa and the analysis period comprises the years between 2010 to 2014. The findings indicated that the CAPM identifies more attractiveness for companies in the agribusiness compared to the market average given by IBovespa. However, the CAPM was efficient to scale the expected returns only in the years 2010, 2011 and 2014, occurring in 2012 and 2013, that the attractiveness appointed by CAPM was significantly lower than the actual return, which can be understood through economic aspects, because the agribusiness sector grown in this period in opposition to the low overall market performance. Finally, it should be noted that the average real return was found to be higher for the brazilian agribusiness companies in relation to the market return in general. At times, they had higher-than-expected real returns and thus were considered attractive for investments by maximizing earnings in the Brazilian stock market.

Keywords: Attraction of investments. CAPM. Agribusiness companies. 


\section{INTRODUÇÃO}

O reconhecido estudo de Markowitz (1952) trouxe a ponderação do risco para a análise e opção de investimentos. De forma mais abrangente, abordou a seleção de uma determinada carteira, que pode ser dividida em duas etapas: a primeira começa com a observação e experiência e finaliza com crenças sobre os desempenhos futuros de títulos disponíveis; a segunda fase, foco deste estudo, inicia com as crenças relevantes acerca de desempenhos futuros e termina com a escolha da carteira. Dessa forma, Markowitz (1952) enfatizou sobre as relações entre crenças e escolhas pautadas em carteiras que considerem retornos esperados e a variância dos retornos (risco).

De forma mais abrangente acerca do CAPM, foi desenvolvido por Sharpe (1964), Lintner (1965) e Mossin (1966) e tem sido um dos modelos mais premiados em finanças (FLETCHER, 1997). Mesmo algumas décadas depois de seu surgimento, o CAPM é ainda amplamente utilizado em aplicações, como para estimar o custo do capital para empresas e avaliar o desempenho de carteiras administradas (FAMA; FRENCH, 2004).

Nesse sentido, Galeno (2010) relata que a base da teoria das carteiras moderna é delineada em um modelo que permite identificar a melhor opção de investimento em situações de risco, ponderando suas preferências individuais. Além disso, como consequência da teoria desenvolvida por Markowitz (1952), vários modelos surgiram com tentativa de quantificar a relação entre risco e retorno, possibilitando, assim, a valoração dos ativos econômicos, com especial atenção ao Capital Asset Pricing Model (CAPM), por ser o mais utilizado (GALENO, 2010).

Para Copeland et al. (2005), o CAPM mede o equilíbrio de mercado que permite a mensuração da fração relevante do risco de um determinado ativo, do prêmio pelo risco, em um certo mercado. No contexto brasileiro, Tambosi Filho, Costa Júnior e Rossetto (2006) relataram que o referido modelo relaciona a rentabilidade esperada de um ativo ou bem, em um mercado em equilíbrio, com seu risco não diversificável, denominado Beta.

Cabe destacar que os primeiros modelos desenvolvidos acerca do CAPM são fundamentais em finanças, mas, atualmente, encontram-se adaptações mais complexas do CAPM (TAMBOSI FILHO; COSTA JÚNIOR; ROSSETTO, 2006). O mais importante disso é que em qualquer abordagem utilizada o CAPM sempre desperta o 
interesse em conhecê-lo melhor, principalmente em contextos e circunstâncias diferentes (ARAÚJO; OLIVEIRA; CASTRO SILVA, 2012).

Empiricamente, no âmbito internacional, a aplicação do CAPM é conhecida com destaque para os estudos de Black, Jensen e Scholes (1972), que fizeram uso de informações derivadas de empresas listadas na Bolsa de Nova Iorque com informações do período de 1926 a 1966, e para os de Fama e MacBeth (1973), que verificaram os retornos mensais das ações de organizações listadas na Bolsa de Nova Iorque entre 1926 e 1968 e que, em ambos, o modelo CAPM foi validado. Contudo, é importante relatar que outras pesquisas, como as de Banz (1981) e Lakonishok e Shapiro (1986), em seus trabalhos empíricos, detectaram problemas na aplicabilidade e validade do modelo CAPM. Em suma, relataram que nem o risco tradicional (Beta) e nem as medidas de risco alternativas (variância ou desvio padrão residual) possuem potencial para explicar a variação transversal dos retornos.

No contexto brasileiro, o CAPM passou a ser utilizado em pesquisas nas últimas décadas e, atualmente, tem sido um tema recorrente nos estudos de Contabilidade e Finanças (ARAÚJO; OLIVEIRA; CASTRO SILVA, 2012). Assim, como no âmbito internacional, os achados em pesquisas nacionais também têm sido distintos. Silva et al. (2009), por meio da criação de cinco carteiras hipotéticas (clusters) de empresas listadas na Bolsa de São Paulo e dimensionando o risco pelo Beta, constataram que as carteiras formadas sustentaram um desempenho percentual em conformidade com o esperado. Em contrapartida, Galdi e Securato (2007) verificaram a relação entre o risco idiossincrático e o retorno de uma carteira diversificada de ativos no mercado de capitais brasileiro e não encontraram evidências de que o risco contribui para o retorno na referida amostra. Há de se ressaltar, ainda, que além de estudos com carteiras de ativos, existem pesquisas que testam ativos individuais, conforme destacado por Fortunato, Motta e Russo (2009), com títulos constantes no IBovespa.

Diante de tais aspectos, identificam-se lacunas de pesquisa na literatura que norteiam a seguinte questão-problema para o estudo: qual é a atratividade nos retornos dos investimentos de empresas brasileiras do agronegócio com o uso do modelo $C A P M$ ? Visando responder ao problema de pesquisa elaborado, teve-se por objetivo verificar a atratividade nos retornos dos investimentos de empresas brasileiras do agronegócio com o uso do modelo CAPM.

O estudo justifica-se pela importância do tema, pois a previsão da taxa de retorno dos ativos é um fator primordial na decisão de investimento. Um modelo de precificação incorreto tende a levar o investidor a tomar decisões equivocadas, fazendo com que este superestime ou subestime a taxa de retorno de suas aplicações 
(GALENO, 2010). Nesse sentido, faz-se uso do CAPM, que oferece previsões poderosas e intuitivamente agradáveis sobre como medir a relação entre o risco e o retorno esperado (FAMA; FRENCH, 2007).

Além disso, no cenário brasileiro, o agronegócio é uma atividade próspera, segura e rentável, vista como uma interessante oportunidade de investimento (WANDERLEY; SILVA; LEAL, 2012), justificando, assim, a importância de estudo no setor. Destaca-se ainda que, em uma perspectiva para os próximos 10 anos, o agronegócio direciona seu foco na competitividade e modernidade, na manutenção do Brasil como um dos principais fornecedores de alimentos e matérias-primas no mundo todo (MINISTÉRIO DA AGRICULTURA, PECUÁRIA E ABASTECIMENTO, 2013).

Ademais, destaca-se que o agronegócio brasileiro possui forte representatividade na produção nacional, especialmente no que se refere às exportações (ARAÚJO et al., 2004). Assim, dada a importância estratégica do setor, surge o interesse em avaliar os níveis de risco das empresas do agronegócio, com o intuito de verificar seu comportamento no mercado acionário, bem como levantar implicações de tais informações para os investidores, financiadores, entre outros interessados.

\section{REFERENCIAL TEÓRICO}

Diversas pesquisas já foram realizadas buscando captar a atratividade nos retornos de investimentos de empresas, porém, não se tem estudos recentes relacionados com o setor do agronegócio brasileiro em específico, sendo este primordial para a economia nacional. Para embasamento teórico do assunto, realizou-se busca nas bases Jstor, Scielo, Science Direct, Scopus e Willey Online Library, além de em revistas especializadas sobre o tema, admitindo fundamentar o estudo com pesquisas relevantes publicadas em periódicos de alto impacto.

\subsection{AVALIAÇÃO DE INVESTIMENTOS E O CAPM}

As decisões tomadas pelos gestores afetam significativamente a atividade organizacional (MARTINSONS; DAVISON, 2007) e na criação das oportunidades de negócios os investimentos são fundamentais, necessitando uma análise adequada para estabelecer sua real atratividade (OJALA; HALLIKAS, 2006). Para isso, existem métodos de avaliação que capturam os componentes que contribuem para estabelecer o 
valor de mercado que se aproxime do valor de realização dos investimentos diante do ambiente altamente competitivo e incerto (SMIT; TRIGEORGIS, 2004).

A atratividade dos investimentos está relacionada à estimativa da taxa de retorno esperada estabelecida pelo custo de capital próprio. Tal custo é uma taxa de retorno mínima requerida pelos investidores, equiparada ao custo de oportunidade que o investidor teria se aplicasse o investimento em um projeto alternativo (SILVA; QUELHAS, 2006).

Além disso, o retorno de um investimento deve considerar uma gama de fatores de risco sobre demanda, preços, custos de matéria-prima e também variáveis macroeconômicas as quais exercem força sistemática sobre os preços das ações (IBRAHIM; AZIZ, 2003). Por conseguinte, existem diferentes formas de se avaliar o retorno dos investimentos, e um dos modelos mais consagrados na literatura acadêmica é o Modelo de Precificação de Ativos de Capital - Capital Asset Pricing Model (CAPM), conhecido pela sua facilidade de aplicação (KRISTJANPOLLER; MORALES, 2011). Portanto, o CAPM foi desenvolvido por Sharpe (1964), Lintner (1965) e Mossin (1966) como um dos modelos de precificação de ativos mais importantes e debatidos (ELTON et al., 2004). Fama e French (2007) relatam que a ampla utilização do CAPM está no fato de que este oferece previsões intuitivas sobre a medida do risco e a relação entre retorno e risco.

A academia moderna de finanças é construída sobre a proposição de que os mercados são fundamentalmente racionais. O modelo fundamental da racionalidade do mercado é o CAPM. Ao capturar a ideia de que os mercados são inerentemente racionais, o CAPM fez das finanças um assunto adequado para estudos econométricos. A indústria tem contato com a aplicação do CAPM para determinar as taxas de desconto, a valorização dos investimentos na própria empresa e, adicionalmente, a valorização da própria empresa, a fim de fixar os preços de venda na regulação dos serviços públicos, bem como para fins de gestores de fundos de benchmarking e executivos estabelecerem bônus ligados à agregação de valor econômico (DEMPSEY, 2013).

O CAPM determina que é possível estimar o retorno esperado para qualquer ativo por uma regressão linear de três variáveis: o Beta (que mede a sensibilidade do ativo em relação à carteira de mercado); a taxa de retorno do ativo livre de risco; e o retorno esperado para a carteira de mercado. Assim, o modelo é tido como um único fator, isto é, o Beta, que explicaria as diferenças nos retornos dos ativos (ELTON et al., 2004).

Pode-se afirmar que o CAPM evoluiu a partir de Sharpe (1964), que se baseou em Markowitz (1959), e ainda levou em consideração outros trabalhos como os de Tobin (1958), Treynor (1961), Lintner (1965), Mossin (1966) e Black, Jensen e 
Scholes (1972), que contribuíram com suas inferências conceituais. Com isso, Sharpe (1964) modificou os pressupostos de finanças, pois mediante uma simples equação consegue determinar a relação risco e retorno. Essa teoria de precificação de ativos foi de grande importância para o campo das finanças modernas.

Mais especificamente, foi sobre as teorias da utilidade e da hipótese da eficiência de mercado que o CAPM foi originado e constituiu seus fundamentos (COSTA JUNIOR; MENEZES; LEMGRUBER, 1993). Com ele, considerou-se que, em situação de equilíbrio, a expectativa de retorno de um ativo seria igual ao retorno de um ativo livre de risco, somado a um prêmio pelo risco assumido, o qual seria fruto da diferença entre o retorno da carteira de mercado e o ativo livre de risco, ponderado pelo Beta (coeficiente de risco sistemático), sendo que o Beta seria considerado como a medida de sensibilidade de risco da empresa (BRUNI, 1998).

Cabe destacar que o CAPM possibilita uma aplicabilidade que atende tanto às necessidades relativas às decisões financeiras empresariais quanto às de investidores (pessoas físicas). Conforme Tomazoni e Menezes (2002), o CAPM, com a presunção de que os investidores são racionais, aponta para uma expectativa que estes, por meio de associações entre a taxa livre de risco e o portfólio de mercado construirão seus portfólios pessoais. Porém, é essencial ressaltar que será o nível que os investidores possuem de aversão ao risco que definirá a forma de alocar seus recursos. Logo, o risco individual do ativo está relacionado ao portfólio de mercado, o qual será adequado ao portfólio do investidor.

De forma mais abrangente acerca do Beta, Sharpe, Alexander e Bailey (1995) e Tomazoni e Menezes (2002) indicam que ele mensura a volatilidade dos retornos do ativo de forma relativa aos retornos do portfólio de mercado. Logo, trata-se de uma métrica de risco sistemático e, como consequência, não pode ser extinto a partir de uma diversificação de ativos. Com o Beta, é possível estimar o risco total (diversificável + não diversificável) de um ativo ou portfólios, pois permite associar o risco sistemático ao não sistemático, o qual pode ser eliminado com a diversificação de ativos.

Em suma, Amaral et al. (2004) indicam que as decisões financeiras mais importantes devem ser estudadas à luz da expectativa de retorno, do risco e dos efeitos dessa associação ao valor do ativo. Além disso, Costa Junior, Menezes e Lemgruber (1993) consideraram que a teoria de carteiras e os modelos de preços criados a partir dessa teoria são, sem dúvida, duas das mais importantes contribuições ligadas ao mercado de capitais, ressaltando, ainda, que após a teoria de carteiras, apareceram vários modelos de preços fundamentando que o trade-off entre o retorno esperado e o risco 
é o mesmo para todos os ativos de mercado, como é o caso do CAPM, utilizado nesta pesquisa.

Conclusivamente, pode-se relatar que os principais modelos de precificação de ativos, CAPM e APT, utilizam-se de informações exógenas para determinar a relação de equilíbrio risco-retorno. Estes usam pressupostos rígidos a fim de manter sua possível aplicação. Nos estudos de mercado, a ausência de oportunidades de arbitragem e a racionalidade do mercado são tidos como pressupostos do CAPM. Contudo, deve-se esclarecer que há críticas a tais pressupostos, principalmente quanto a suposições inconsistentes com a realidade do mercado, conforme mencionado por Haugen e Baker (1996).

No próximo tópico será discorrido sobre o caminho trilhado pelos estudos que têm buscado utilizar o CAPM para a precificação de ativos, quais os principais métodos aplicados e seus achados, possibilitando uma visão macro da pesquisa nessa área até o momento.

\subsection{ESTUDOS ANTERIORES}

Primeiramente, foram considerados alguns estudos anteriores que abordaram a efetividade do modelo CAPM em comparação com modelos alternativos para a avaliação dos retornos de investimentos. Nessa premissa, são elencados estudos nacionais que têm efetuado tal comparação, como a pesquisa de Tambosi Filho, Costa Júnior e Rossetto (2006), que apresentaram as vantagens dos modelos condicionais em relação ao modelo estático, e destacaram que o modelo condicional (C-CAPM) apresenta maior eficiência nas previsões dos ativos financeiros e dos retornos de investimentos em comparação com o modelo CAPM.

Fama e French (1996) relatam que estudos anteriores mostram que o retorno médio das ações está relacionado a características de tamanho da firma, lucro/preço, fluxo de caixa/preço, book-to-market e crescimento das vendas passadas. Os autores questionam a falta de explicação de tais padrões pelo modelo CAPM. Os achados demonstram que, com exceção dos retornos de curto prazo, as anomalias desaparecem, em grande parte, com o uso de um modelo que considere três fatores.

Na sequência são elencados alguns estudos internacionais que efetuaram comparações de modelos para a avaliação dos retornos de carteiras de investimentos. Os autores Sauer e Murphy (1992) investigaram o poder explicativo do modelo $C A P M$, e concluíram que o modelo que melhor explica as relações de risco e retorno no mercado de ações alemão é o modelo condicional (C-CAPM). Por sua vez, Sun e 
Zhang (2001) utilizaram o modelo CAPM e APT para avaliar o desempenho financeiro em investimentos relacionados com a silvicultura, sendo que os resultados indicam que o modelo $A P T$ é mais robusto para tal estimativa de retorno dos investimentos.

Apesar de tal evidência, o modelo CAPM tem sido utilizado, com frequência, no contexto do mercado de capitais brasileiro, e para esta pesquisa foi estimada sua aplicabilidade para responder ao objetivo proposto, vislumbrando que pode ser útil para estimar a atratividade dos retornos de investimento em empresas do agronegócio brasileiro.

Visto que o foco do estudo não estabelece a comparação da eficiência entre modelos de precificação de ativos financeiros concorrentes, mas vislumbra observar a atratividade nos retornos de investimentos das organizações do agronegócio brasileiro, apresentam-se alguns estudos focados em tal discussão, que poderão nortear a discussão.

Araújo et al. (2004) avaliaram o risco de mercado de empresas do agronegócio brasileiro por meio do uso do CAPM e GARCH-M. O modelo GARCH-M mostrou-se mais robusto do que o C-CAPM condicional, contudo, a capacidade preditiva dos modelos não apresentou evidências de haver superioridade por parte de um determinado modelo. Os Betas das empresas do agronegócio sinalizaram potencial com a finalidade de redução do risco sistemático em carteiras de renda variável. Por fim, os resultados denotam a atratividade de novas captações de recursos no mercado financeiro, viabilizando o crescimento sustentável e a redução no custo de capital das empresas do agronegócio nacional.

Rostagno, Kloeckner e Becker (2004) examinaram a hipótese de previsibilidade de retorno das ações negociadas na Bovespa, considerando que há evidências de que inúmeros fatores explicam os diferenciais nos retornos mensais das ações da amostra. Os fatores elencados foram: capitalização de mercado, tendência do volume de negociação, relação dividendos/preço das ações, tendência da relação dividendos/ preço das ações, relação fluxo de caixa/preço das ações e excesso de retorno em 3 e 12 meses. De maneira geral, contrapondo com os pressupostos, os fatores de risco não apresentaram poder de explicação para os retornos mensais. Por fim, testes adicionais indicam que os portfólios com maiores retornos não são necessariamente os mais arriscados, sugerindo erros na previsão das ações no mercado acionário brasileiro.

A ideia central de Ross (1976) em desenvolver o modelo Arbitrage Pricing Theroy (APT) com o intuito de superar as falhas e limitações do modelo CAPM, incorporou a observação de múltiplos fatores advindos de diversas fontes de risco dos ativos da economia e foi também testada por Rostagno, Kloeckner e Becker (2004). 
De acordo com os achados, esse modelo não foi tão útil, pois os resultados dos autores demonstram que os fatores adicionais não exerceram impacto sobre a precificação dos portfólios pesquisados.

De forma divergente, Dhankar e Singh (2005) concluem que o APT, por meio do uso de múltiplos fatores, proporciona uma melhor indicação de risco de ativos e estimativas de taxa de retorno. Já Paiva (2005) analisou o CAPM e o Downside Capital Asset Pricing Model ( $D$-CAPM), e avaliou que o $D$-CAPM é uma alternativa eficiente para a precificação de ativos. Logo, concluiu que o $D$-CAPM possui uma maior capacidade explicativa para os retornos dos ativos se comparado com o CAPM.

A investigação da validade do modelo de precificação de ativos sob o fator de mercado, o tamanho da empresa, o índice book-to-market e o desempenho acumulado dos retornos das ações foi metodologia feita por Santos, Famá e Mussa (2012), os quais concluiram que as evidências sobre o modelo foram válidas para o mercado acionário brasileiro, sendo superior ao modelo tradicional CAPM na explicação das variações dos retornos das ações.

Já Forster (2009) teve o objetivo de estudar a apuração do custo de oportunidade do capital próprio, utilizando-se da metodologia proposta pelo CAPM. Os principais aspectos característicos em mercados emergentes que podem influenciar os indicadores do CAPM foram identificados. Foi demonstrada a apuração do custo de oportunidade do capital próprio das ações ordinárias das empresas Petrobras e Vale do Rio Doce. Os resultados apontam que apesar das várias críticas ao modelo CAPM, ele permite a apuração do custo de oportunidade do capital próprio.

Araújo, Oliveira e Castro Silva (2012) argumentam que, no Brasil, o modelo de precificação de ativos financeiros $(C A P M)$ tem sido um tema recorrente nos estudos em Contabilidade e Finanças. Os autores realizaram um levantamento de artigos acadêmicos sobre o CAPM e variantes no País, entre 1997 e 2008, apresentados no congresso EnAnpad e em periódicos nacionais. Os resultados indicaram que em quase 1/3 dos trabalhos houve comparações do CAPM com outros modelos. A versão convencional foi a mais utilizada e, naqueles que confirmaram a efetividade da teoria, a análise foi cross-section; o IBovespa foi usado como proxy da carteira de mercado e a taxa Selic como proxy do ativo livre de risco. Por outro lado, naqueles artigos que refutaram a teoria, o foco de análise foi cross-section, sendo IBovespa e CDI as proxies mais aplicadas.

De maneira geral, Araújo, Oliveira e Castro Silva (2012) concluíram que o modelo tem sido satisfatório no País, apesar de alguns elementos não estarem de acordo com os pressupostos teóricos. Tais resultados ratificam a utilização do CAPM neste 
trabalho como o método para mensurar a atratividade nos retornos dos investimentos de empresas brasileiras do agronegócio.

Dempsey (2013) estabelece críticas ao modelo CAPM, em que o modelo de precificação de ativos de capital é utilizado para afirmar que os ativos estariam com preços condizentes com um trade-off entre risco e expectativa de retorno do investimento. $\mathrm{O}$ autor indica que ao aderir ao modelo CAPM se estaria escolhendo encontrar um mercado muito próximo dos nossos próprios termos de racionalidade, em vez de um mercado imperfeito como ocorre na realidade.

Machado e Machado (2014) analisaram se o modelo de dois fatores desenvolvidos por Liu (2006) explica as variações dos retornos das ações no mercado acionário brasileiro. O objetivo secundário foi comparar o desempenho do modelo de dois fatores de Liu (2006) com o do CAPM e com o de três fatores de Fama e French (1996), bem como investigar se o modelo é robusto com as estratégias baseadas no tamanho da empresa, book-to-market, estratégia atual, lucro/preço, fluxo de caixa/preço, liquidez e alavancagem. Os resultados indicam uma melhoria no poder explicativo do modelo de dois fatores em relação ao CAPM e um desempenho próximo ao modelo de três fatores, mesmo que o modelo de dois fatores não tenha explicado as anomalias documentadas pela literatura.

Farias, Moura e Figueiredo (2018) aplicaram o Modelo de Precificação de Ativos de Capital (CAPM), utilizando como ferramentas os balanços patrimoniais de empresas de construção civil, no período relativo aos anos 2009 e 2010. Os achados apontaram para ambas as empresas, no período em estudo, um Beta inferior a 1, ou seja, risco menor que o risco do mercado.

Silva et al. (2017) buscaram identificar se o CAPM serve como benchmark para captar o retorno das ações no mercado de capitais brasileiro, já que esse mercado é considerado um mercado emergente de volatilidade constante, corrupção e outros fatores que podem impactar o resultado. A amostra continha 96 empresas de capital aberto do novo mercado, e o modelo estatístico utilizado foi a regressão linear múltipla com dados em corte transversal, para os anos de 2010 a 2016. Os resultados mostraram que o CAPM tem significância estatística para a variável de interesse Beta. O modelo proposto pôde explicar 34,9\% da variável CAPM que pode ser justificada pela heterocedasticidade dos dados. Esses resultados ressaltam a importância para um investidor em utilizar o CAPM na busca de um custo mínimo para o retorno de seus investimentos.

Linhares (2018), em seu estudo, investiga os Socially Responsible Investiment que são estratégias de investimentos que consideram, juntamente com análises econômico-financeiras, fatores de desempenho ambiental, social e de governança 
corporativa, denominados investimentos ESG. O artigo objetiva verificar se os investimentos em ações de empresas classificadas como ESG apresentam desempenho financeiro superior às demais. Para a realização dos testes empíricos foram utilizadas as metodologias de Alfa de Jensen e o CAPM para verificar a relação de risco e retorno das carteiras ESG em relação às demais carteiras nos países desenvolvidos e nos países emergentes selecionados. Os resultados indicaram que os investimentos em empresas ESG apresentam desempenho financeiro no longo prazo superior às demais, tanto para países emergentes quanto para os desenvolvidos, com exceção dos Estados Unidos da América. No entanto, os valores de retorno ajustados a risco foram estatisticamente significativos apenas para os países emergentes e para o Canadá.

Esses estudos mais recentes que continuam utilizando o CAPM demonstram que a despeito de outras técnicas poderem ter um ou outro benefício adicional, o $C A P M$, para investigações em empresas brasileiras, no que se refere à análise de retornos ajustados a risco, persiste como um método útil e aplicável na construção de tal conhecimento.

A seguir se fará a descrição dos métodos utilizados no trabalho com enfoque na composição da amostra e o modelo com as regressões a serem utilizadas para se verificar a análise da atratividade dos retornos dos investimentos.

\section{PROCEDIMENTOS METOdOLÓGicos}

A fim de se verificar o retorno dos investimentos em empresas brasileiras do agronegócio com o uso do modelo CAPM, que gera atratividade para os investidores, este estudo é delineado quanto aos objetivos como descritivo por observar variáveis sem as manipular. A abordagem do problema é determinada como quantitativa, uma vez que faz uso de técnicas estatísticas e, por fim, os procedimentos são de análise documental, pois as informações utilizadas foram extraídas da base de dados Economática e do website do Banco Central do Brasil (BCB).

A população do estudo corresponde a todas as empresas de capital aberto que constam nos setores de “Agro e Pesca” e “Alimentos e Bebidas” conforme classificação setorial da Economática que, posteriormente, foram confrontadas com os subsetores de “agropecuária” e “alimentos processados” do website da BM\&FBovespa, a fim de delinear com maior exatidão as organizações do agronegócio brasileiro, totalizando 22 empresas. Para o delineamento da amostra, foram excluídas as empresas que não possuíam todas as informações necessárias para a operacionalização do modelo 
CAPM, o que resultou em 13 empresas. Dessa forma, para um melhor delineamento, apresentam-se no Quadro 1 as empresas e suas respectivas classes de ações:

Quadro 1 - Empresas e ações que compõem a amostra da pesquisa

\begin{tabular}{|c|c|}
\hline Empresa & Classe de ação \\
\hline Brasil Agro & ON \\
\hline BRF AS & ON \\
\hline Cosan & ON \\
\hline Cosan Ltda. & ON \\
\hline Excelsior & PN \\
\hline JBS & ON \\
\hline M. Dias Branco & ON \\
\hline Marfrig & ON \\
\hline Minerva & ON \\
\hline Minupar & ON \\
\hline Renar & ON \\
\hline São Martinho & ON \\
\hline SLC Agrícola & ON \\
\hline
\end{tabular}

Fonte: os autores.

A análise de dados abrange cinco anos, mais especificamente de 2010 a 2014, sendo utilizadas as cotações das ações de fechamento de cada mês coletadas na base de dados Economática. Os dados foram analisados anualmente, pautados em estudos anteriores, como, por exemplo, de Herrera e Téllez (2009).

Nesse sentido, com o intuito de verificar a análise da atratividade dos retornos dos investimentos, tem-se, então, o modelo CAPM, que conforme Ross, Westerfield e Jaffe (1995, p. 226), é representado conforme a fórmula a seguir:

$$
R_{e}=R_{F}+\beta\left(R_{e M}-R_{F}\right)
$$

Em que:

$R_{e}=$ Retorno esperado de um título;

$R_{F}=$ Retorno do ativo sem risco;

$\beta=$ Beta do título;

$\left(R_{\theta M}-R_{F}\right)=$ Diferença entre o retorno esperado da carteira de mercado e a taxa livre de risco. 
O retorno do ativo sem risco foi determinado conforme a taxa Selic anual para os períodos de estudo, sendo esta extraída do website do Banco Central do Brasil. O retorno esperado da carteira de mercado, por sua vez, corresponde ao índice IBovespa, nesse caso também medido de para cada ano. Cabe destacar que, conforme Araújo, Oliveira e Castro Silva (2012), em levantamento dos artigos acadêmicos acerca do CAPM no Brasil, a Selic tem sido utilizada como a proxy preferida para o ativo livre de risco, e o IBovespa é a proxy da carteira de mercado utilizada com maior intensidade, o que corrobora as escolhas realizadas para esta pesquisa.

Por fim, ainda se tem o coeficiente Beta constante na equação suprarreferida dada por Ross, Westerfield e Jaffe (1995, p. 226), medindo o risco relevante de uma determinada ação, que de acordo com Ehrhardt e Brigham (2012), pode ser determinado conforme a fórmula a seguir:

$$
\boldsymbol{\beta}_{i}=\left(\frac{\sigma_{i}}{\sigma_{M}}\right) \boldsymbol{p i M}
$$

Em que:

$\beta_{\mathrm{i}}=$ Coeficiente Beta do investimento $i$;

$\sigma_{i}=$ Desvio padrão do retorno da ação $i$;

$\sigma_{\mathrm{M}}=$ Desvio padrão do retorno do mercado;

piM = Correlação entre o retorno do investimento $i$ e o retorno do mercado.

O desvio padrão do retorno da ação e do retorno do mercado é dado pela relação entre o preço/valor do título/índice do mês $t$ dividido por $t$-1, estabelecido à variação em números percentuais. Ademais, destaca-se ainda que os Betas foram calculados utilizando o método estatística de regressão pelo software especializado Stata 14, além do uso do software Microsoft Excel 2007 para a tabulação e a realização dos demais cálculos.

\section{DESCRIÇÃO E ANÁLISE DE DADOS}

Primeiramente, executou-se o cálculo dos Betas, baseando-se na taxa Selic para delinear a taxa livre de risco, e no índice IBovespa, com o intuito de representar o retorno do mercado. Cabe destacar que o IBovespa é o indicador de desempenho 
médio das cotações dos ativos de maior negociabilidade e representatividade no mercado de ações brasileiro (BM\&FBOVESPA, 2015).

Para a compreensão dos achados que serão posteriormente apresentados, Securato (1996) e Samanez (2006) classificam os Betas positivos em três categorias: defensivo - é classificado quando o valor do Beta for menor que 1, em que o retorno dele seria inferior ao indicador de mercado; médio - é classificado quando o valor do Beta for igual a 1, determinando que ele possui comportamento semelhante ao do mercado; ofensivo - é classificado quando o valor do Beta for maior que 1, estimando comportamento agressivo do Beta em relação ao índice de mercado.

Ademais, destaca-se que em alguns casos o Beta pode ser estimado com valor negativo, determinando que a empresa possui posicionamento de mercado contrário ao índice utilizado, nesse caso, o IBovespa. Dessa forma, Schivinski (2002) corrobora mencionando que empresas que apresentam Beta negativo variam no sentido oposto ao do mercado. Diante das inferências teóricas abordadas sobre o Beta, apresenta-se a estatística descritiva dos valores obtidos com o seu cálculo, conforme a Tabela 1:

Tabela 1 - Estatística descritiva dos Betas das empresas do agronegócio entre 2010 e 2014

\begin{tabular}{lrrrrr}
\hline Período & $\mathbf{2 0 1 0}$ & $\mathbf{2 0 1 1}$ & $\mathbf{2 0 1 2}$ & $\mathbf{2 0 1 3}$ & $\mathbf{2 0 1 4}$ \\
\hline Média & 0,327436 & 0,738439 & 0,537763 & 0,629241 & 0,877338 \\
Mínimo & $-0,602288$ & $-0,789835$ & $-0,056416$ & $-1,077108$ & 0,051732 \\
Máximo & 1,029001 & 2,779197 & 1,407696 & 2,721939 & 1,508284 \\
\hline Fonte: os autores. & & & & &
\end{tabular}

Conforme a Tabela 1, verifica-se que a maior média do Beta das empresas do agronegócio ocorreu no ano 2014 (0,877338), enquanto a menor média foi encontrada em 2010 (0,327436). De maneira geral, as evidências indicam que as empresas do agronegócio tendem a ser defensivas, o que indica que os retornos dos investimentos de tais organizações seriam inferiores ao indicador de mercado (SECURATO, 1996; SAMANEZ, 2006; ALENCASTRO, 2009). Além disso, os achados demonstram que houve crescimento nos Betas das empresas do agronegócio durante o período analisado, apontando para uma aproximação dos retornos dos investimentos com o indicador de mercado, visto que em 2014 a média dos Betas se aproximou de $1(0,877338)$, que sinaliza Betas com risco médio.

Ao analisar os valores mínimos e máximos dos Betas encontrados nas empresas estudadas, tem-se em 2013 um título que apresentou o menor Beta (-1,077108). O resultado indica que há uma tendência para tal organização em obter retornos divergentes ao indicador de mercado (SCHIVINSKI, 2002). Por outro lado, o maior Beta 
identificado foi no ano 2011, com 2,779197, sendo este classificado como ofensivo. Nesse caso, a tendência é de que para tal organização o indicador de retorno do investimento seria maior que o indicador de mercado, contudo, caso o índice de mercado esteja em declínio, o investidor tenderá a um maior risco de perda em seu investimento (SECURATO, 1996; SAMANEZ, 2006; ALENCASTRO, 2009).

Posteriormente, tem-se a taxa Selic e o índice IBovespa entre os anos 2010 e 2014. Conhecer a variação de tais indicadores é importante, visto que influenciam o cálculo do retorno esperado do modelo CAPM, conforme demonstrado nos procedimentos metodológicos desta pesquisa. Para tanto, tem-se as informações contidas na Tabela 2:

Tabela 2 - Taxa Selic e IBovespa entre 2010 e 2014

\begin{tabular}{lrrrrr}
\hline Taxa/Índice & $\mathbf{2 0 1 0}$ & $\mathbf{2 0 1 1}$ & $\mathbf{2 0 1 2}$ & $\mathbf{2 0 1 3}$ & $\mathbf{2 0 1 4}$ \\
\hline Selic & $9,7328 \%$ & $11,6209 \%$ & $8,4629 \%$ & $8,1814 \%$ & $10,8559 \%$ \\
IBovespa & $1,0439 \%$ & $-18,1086 \%$ & $7,3968 \%$ & $-15,4958 \%$ & $-2,9122 \%$ \\
\hline Fonte:
\end{tabular}
Fonte: os autores.

De acordo com a Tabela 2, nota-se que a taxa Selic no período analisado ficou entre o mínimo de 8,1814\% e o máximo de 11,6209\% nos anos 2013 e 2011, respectivamente. Cabe destacar que a taxa Selic representa o principal determinante das taxas de juros praticados pelo mercado, sendo estabelecida pelo Banco Central (FERNANDES; TORO, 2005).

O IBovespa, por sua vez, sendo este o retorno médio de mercado, teve o menor índice (-18,1086\%) no ano 2011 e o maior (7,3968\%) em 2012. Conforme dados da BM\&FBovespa (2011), o IBovespa em 2011 foi impactado negativamente pela conjuntura do cenário macroeconômico. Para compreender essa assertiva, destaca-se principalmente a intensificação da crise europeia, com rumores de que a Grécia decretaria calote de suas dívidas, assim como a sinalização de problemas em países como Espanha, Itália e Portugal.

Apesar do baixo desempenho de mercado em 2011 verificado pelo IBovespa, houve uma recuperação no ano 2012 em que o índice foi positivo, sendo o melhor no período em análise. Em 2013 foi verificada nova queda considerável no IBovespa de -15,4958\%, cujo impacto, conforme Mendonça e Abrão (2015), pode ter sido ocasionado pela instabilidade macroeconômica que dificultou o crescimento linear de longo prazo. Esse fato, portanto, impulsiona a instabilidade verificada no mercado acionário brasileiro, conforme o IBovespa. 
Após o cálculo dos Betas e com conhecimento da taxa Selic e do índice IBovespa, foi possível estabelecer o cálculo do retorno esperado por meio do modelo CAPM. Os resultados de tal aplicação estão demonstrados na Tabela 3:

Tabela 3 - Retorno esperado pelo CAPM para as empresas do agronegócio entre 2010 e 2014

\begin{tabular}{lrrrrr}
\hline Período & $\mathbf{2 0 1 0}$ & $\mathbf{2 0 1 1}$ & $\mathbf{2 0 1 2}$ & $\mathbf{2 0 1 3}$ & $\mathbf{2 0 1 4}$ \\
\hline $\begin{array}{l}\text { Média do } \\
\text { retorno Espe- } \\
\text { rado }\end{array}$ & $6,8877 \%$ & $-10,3325 \%$ & $7,8896 \%$ & $-6,7173 \%$ & $-1,2234 \%$ \\
\hline $\begin{array}{l}\text { Fonte: os autores. } \\
\text { Pod }\end{array}$ & & & & & \\
\hline
\end{tabular}

Observa-se na Tabela 3 que em dois anos (2010 e 2012) a atratividade das empresas do agronegócio brasileiro, de acordo com o modelo CAPM, foi positiva, enquanto em três exercícios foi negativa (2011, 2013 e 2014). Contudo, mesmo nos anos em que o retorno esperado foi positivo, apresentou-se menor que a Selic do respectivo período. O resultado indica que os investidores das empresas do agronegócio estão aceitando determinado nível de risco no mercado e obtendo uma atratividade esperada inferior à taxa livre de risco (Selic) do País.

Os resultados apresentados podem ter sofrido interferência pela constante baixa no índice IBovespa, visto tal fator ser considerado no cálculo da atratividade nos retornos esperados do modelo CAPM. Diante do fato, o baixo indicador de mercado (IBovespa) representa que uma parcela significativa de empresas, com altas negociações na bolsa de valores, está com retornos abaixo no normal. O IBovespa, sendo afetado por parcela significativa de empresas, faz com que haja impacto negativo no cálculo do retorno esperado para as empresas do agronegócio, mesmo que o setor prospecte resultados satisfatórios.

Corroborando as conclusões anteriores, ressalta-se que apesar dos baixos retornos esperados pelo modelo CAPM para o setor de agronegócio, em todos os períodos se apresentaram maiores que o índice IBovespa. Isso ocorre, principalmente, em razão de as empresas terem apresentado Beta negativo e/ou defensivo (menor que 1), sendo que o Beta negativo demonstra que as empresas variam em sentido contrário ao mercado (SCHIVINSKI, 2002), ou seja, quando o mercado está em declínio, como ocorrido em 2011, 2013 e 2014, tais organizações apresentam alta atratividade, e aquelas com Beta defensivo tendem a apresentar redução na oscilação das ações e a sofrer menor impacto (ALENCASTRO, 2009).

Por fim, para verificar se o modelo CAPM conseguiu prever com eficiência o retorno das empresas em análise, apresenta-se, a seguir, a Tabela 4, na qual constam os retornos reais das ações das empresas do agronegócio por ano: 
Tabela 4 - Retorno real das ações das empresas do agronegócio entre 2010 e 2014

\begin{tabular}{lrrrrr}
\hline Períodos & $\mathbf{2 0 1 0}$ & $\mathbf{2 0 1 1}$ & $\mathbf{2 0 1 2}$ & $\mathbf{2 0 1 3}$ & $\mathbf{2 0 1 4}$ \\
\hline $\begin{array}{l}\text { Média do } \\
\text { retorno Real }\end{array}$ & $4,7240 \%$ & $-11,7200 \%$ & $28,9792 \%$ & $14,3817 \%$ & $-0,9073 \%$ \\
\hline Fonte: os autores. & & & &
\end{tabular}

Comparando os dados das Tabelas 3 e 4, é possível observar que em três períodos de estudo o retorno esperado conforme o modelo CAPM e o retorno real das ações foram próximos em 2010, 2011 e 2014. Especificamente, no ano 2010, o modelo $C A P M$ sinalizou um retorno de $6,8877 \%$, enquanto o real foi de 4,7240\%; em 2011, o CAPM aponta para o retorno de $-10,3325 \%$, sendo que, de fato, teve-se o retorno de -11,7200\%; e, por fim, em 2014, a previsão foi mais próxima, conforme o modelo CAPM, o retorno esperado seria de $-1,2234 \%$ e o real foi de $-0,9073 \%$.

Como esses indicadores foram estabelecidos pela média dos 13 títulos analisados, existem ações que subiram no período e outras que caíram. Assim, o investidor com a posse dos dados obtidos pelo modelo CAPM conseguiria visualizar qual dos títulos apresenta melhor atratividade dentro do limite de risco aceitável pelo investidor com vistas a estabelecer sua carteira ótima a fim de maximizar seu retorno pessoal.

Por outro lado, nos anos 2012 e 2013 verifica-se que a atratividade estimada pelo modelo CAPM é significativamente inferior ao retorno real das ações obtidas pelas empresas do agronegócio brasileiro. De forma mais abrangente, os achados apontaram para um retorno esperado de 7,8896\% em 2012 e -6,7173\% em 2013, enquanto o retorno real foi consideravelmente melhor, com 28,9792\% em 2012 e 14,3817\% em 2013.

A diferença entre o retorno esperado e o retorno real pode ser reflexo de fatores econômicos. Essa suposição converge com Bali e Zhou (2016), que descobriram em seu estudo que carteiras de ações altamente correlacionadas com a incerteza econômica representada pelo prêmio de risco de variância (VRP, Variance Risk Premium) carregam um significativo prêmio de $8 \%$ anualizado em relação às carteiras que estão minimamente correlacionadas com a VRP.

Os achados corroboram autores que argumentam sobre as deficiências do modelo CAPM na consideração de fatores adicionais que contribuem para a efetividade no estabelecimento do retorno esperado dos investimentos, conforme Sauer e Murphy (1992), Fama e French (1996), Dhankar e Singh (2005), Santos, Famá e Mussa (2012) e Machado e Machado (2014). Por outro lado, o modelo CAPM apresentou resultados satisfatórios para a análise de investimento nas empresas do agronegócio em três dos períodos analisados, corroborando as inferências de Araújo, Oliveira e Castro Silva (2012) sobre a aplicabilidade do modelo no contexto brasileiro. 
O Gráfico 1 apresenta uma consolidação dos achados obtidos pela pesquisa durante o período analisado:

Gráfico 1 - Comparação entre o retorno esperado pelo CAPM, retorno real, taxa Selic e índice de mercado IBovespa entre os anos 2010 e 2014

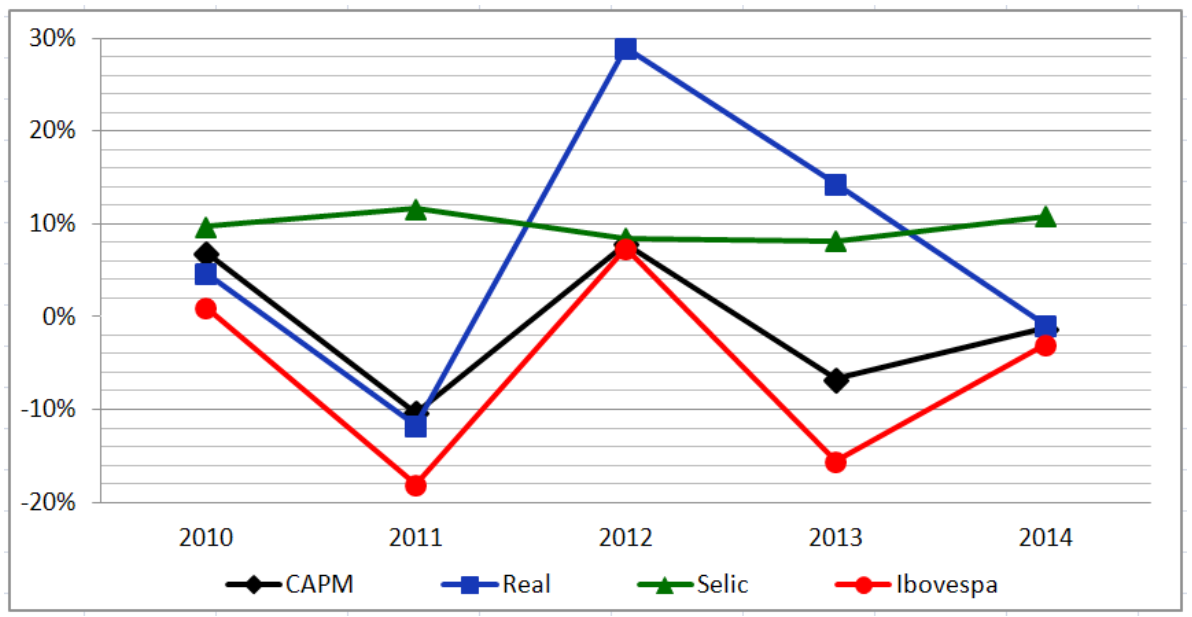

Fonte: os autores.

Desse modo, pode-se inferir uma tendência de que o mercado não prospecta atratividade ideal sobre as organizações que atuam no agronegócio nos anos 2012 e 2013, ou seja, o modelo indica que os retornos de atratividade não têm refletido valorização adequada para o retorno que pode ser alcançado pelas organizações do agronegócio brasileiro.

Além disso, conforme o Gráfico 1, as empresas do agronegócio demonstraram retornos reais satisfatórios para os anos 2012 e 2013, refletindo o bom momento do setor. Nesses anos, os investidores obtiveram retornos médios acima da taxa Selic, acima do IBovespa e, também, superior ao esperado pelo risco atrelado a tais títulos conforme o modelo CAPM. Nos demais anos, os retornos reais médios não foram tão satisfatórios, contudo, superiores à média do mercado dada pelo IBovespa.

De maneira geral, os resultados confirmam as evidências de Araújo et al. (2004) para as empresas do agronegócio, em que tais organizações sinalizam potencial para a redução do risco nas carteiras de investimento, e a atratividade para a captação de novos recursos no mercado acionário, reduzindo o custo de capital e proporcionando crescimento sustentável. 


\section{CONSIDERAÇÕES FINAIS}

Neste artigo teve-se por objetivo verificar a atratividade nos retornos dos investimentos de empresas brasileiras do agronegócio com o uso do modelo CAPM. Para tanto, fez-se cálculo dos Betas para medir o risco dos ativos, conforme metodologia proposta por Ehrhardt e Brigham (2012). Posteriormente, a atratividade das ações de empresas do agronegócio brasileiro foi estimada conforme o modelo CAPM proposto por Ross, Westerfield e Jaffe (1995, p. 226), tendo-se o índice IBovespa como o retorno médio de mercado e a taxa Selic como a taxa livre de risco.

Os achados dados pelo modelo CAPM demonstram que as empresas do agronegócio brasileiro são mais atrativas do que a média do mercado, que é dada pelo índice IBovespa, indicador de desempenho médio das cotações dos títulos de maior negociabilidade e representatividade no mercado acionário brasileiro (BM\&FBovespa, 2015). Contudo, os retornos esperados dados pelo modelo foram próximos dos reais apenas para três dos cinco períodos analisados, sendo 2010, 2011 e 2014.

Nesse sentido, para os referidos períodos, o CAPM refletiu adequadamente os retornos médios dos 13 títulos das empresas do agronegócio brasileiro. Assim, os resultados sugerem que o modelo possa ser eficiente para investidores analisarem quais ações teriam retornos melhores, podendo tomar suas decisões de forma adequada, buscando ativos que possuem atratividade desejada dentro do risco máximo aceitável para o investidor. Dessa forma, o CAPM, neste trabalho, e em específico neste corte temporal, mostrou-se interessante para investidores conseguirem montar sua carteira de ações inserindo empresas do agronegócio brasileiro, visando maximizar seus ganhos.

Contudo, para os anos 2012 e 2013, a atratividade medida pelo CAPM não foi ideal, pois os retornos reais das ações das empresas do agronegócio brasileiro foram, em média, relevantemente superiores aos retornos esperados. Este resultado pode ser creditado ao momento de crescimento vivido pelo agronegócio brasileiro nos anos 2012 e 2013, que entrou em contraste com setores importantes para o índice IBovespa, como o elétrico e o de commodities minerais, que também já haviam passado por declínio econômico. Assim, o baixo IBovespa no período reflete no cálculo do $C A P M$, que mesmo considerando outras variáveis, como o Beta, tende a capturar o mau momento do mercado como um todo, refletindo no grau de atratividade das empresas analisadas.

Dessa forma, atenta-se para a importância de que o investidor considere aspectos econômicos ligados a determinado setor em específico, pois estes podem influenciar nos retornos reais das empresas, destoando do momento geral vivido pelo 
mercado dado pelo IBovespa. No geral, pode-se concluir que as empresas do agronegócio brasileiro vêm apresentando, na média do período analisado, retornos reais maiores do que sua atratividade e, principalmente, superiores ao mercado como um todo, sendo títulos interessantes para a aquisição quando dimensionados seus determinantes a fim de maximizar o retorno dos recursos investidos.

Como limitações da pesquisa, tem-se a consideração de apenas cinco anos de análise, pois se a coleta de dados fosse estendida para um período maior, haveria redução no número de empresas com ações negociadas em todo o período, que também é uma limitação, pois considera ações de 13 companhias, número reduzido, mas ainda assim o agronegócio é um dos maiores setores individuais para a análise de empresas listadas na BM\&FBovespa. Por fim, para futuras pesquisas, recomenda-se a utilização do modelo Arbitrage Pricing Theory (APT) desenvolvido por Ross (1976) e que leva em consideração um conjunto de fatores que podem estar relacionados com o retorno de um ativo como, por exemplo, aspectos econômicos (KRISTJANPOLLER; MORALES, 2011), podendo ser comparado com este estudo a fim de avaliar qual dos modelos, $C A P M$ ou $A P T$, possui potencial para medir com maior eficiência a atratividade esperada dos títulos negociados por empresas do agronegócio brasileiro.

\section{REFERÊNCIAS}

ALENCASTRO, D. Análise Empírica do CAPM Básico para o Brasil após a Implantação do Plano Real. 2009. Dissertação (Mestrado em Desenvolvimento Econômico)-Pontifícia Universidade Católica do Rio Grande do Sul, Porto Alegra, 2009.

AMARAL, H. F. et al. Fundos de pensão como formadores de poupança interna: uma alternativa para o financiamento da atividade econômica. Rev. de Administração Contemporânea, v. 8, 2004.

ARAÚJO, D. L. et al. O Risco de Mercado do Agronegócio Brasileiro: uma Análise comparativa entre os modelos CAPM e GARCH-M. Revista Eletrônica de Gestão Organizacional, v. 2, n. 3, 2004.

ARAÚJO, E. A. T.; OLIVEIRA, V. do C.; CASTRO SILVA, W. A. CAPM em estudos brasileiros: Uma análise da pesquisa. Revista de Contabilidade e Organizações, v. 6, n. 15, p. 95-122, 2012.

BALI, T. G.; ZHOU, H. Risk, uncertainty, and expected returns. Journal of Financial and Quantitative Analysis, v. 51, i. 3, p. 707-735, 2016. 
BANZ, R. W. The relationship between return and market value of common stocks. Journal of Financial Economics, v. 9, i. 1, p. 3-18, 1981.

BLACK, F.; JENSEN, M. C.; SCHOLES, M. S. The capital asset pricing model: some empirical tests. Studies in the theory of capital markets: Praeger, 1972.

BM\&FBOVESPA. Índice Bovespa - Ibovespa. Disponível em: <http://www.bmfbovespa.com.br/indices/ResumoIndice.aspx?Indice=IBOVESPA\&idioma=pt-br>. Acesso em: 16 set. 2015.

BM\&FBOVESPA. Relatório Anual 2011. 2011. Disponível em: <http://ri.bmfbovespa.com.br/ptb/901/BMFBovespaRA2011GRIPT.pdf>. Acesso em: 16 set. 2015.

BRUNI, A. L. Risco, Retorno e Equilíbrio: uma Análise do Modelo de Precificação de Ativos Financeiros na Avaliação de Ações Negociadas na BOVESPA (19881996). 1998. Dissertação (Mestrado em Administração)-Universidade de São Paulo, São Paulo, 1998.

COPELAND, T. et al. Financial Theory and Corporate Policy. 4. ed. United States: Addison Wesley, 2005.

COSTA JUNIOR, N. C. A. da; MENEZES, E. A.; LEMGRUBER, E. F. Estimação do Beta de ações através do método dos coeficientes agregados. Revista Brasileira de Economia, v. 47, n. 4, p. 605-621, 1993.

DEMPSEY, M. The capital asset pricing model (CAPM): the history of a failed revolutionary idea in finance? Abacus, v. 49, i. S1, p. 7-23, 2013.

DHANKAR, R. S.; SINGH, R. Arbitrage pricing theory and the capital asset pricing model-evidence from the indian stock market. Journal of Financial Management \& Analysis, v. 18, i. 1, p. 14, 2005.

EHRHARDT, M. C.; BRIGHAM, E. F. Administração Financeira: Teoria e Prática. São Paulo: Cengage Learning, 2012.

ELTON, E. J. et al. Moderna teoria de carteiras e análise de investimentos. São Paulo: Atlas, 2004.

FAMA, E. F.; FRENCH, K. R. Multifactor explanations of asset pricing anomalies. The journal of finance, v. 51, i. 1, p. 55-84, 1996. 
FAMA, E. F.; FRENCH, K. R. O modelo de precificação de ativos de capital: teoria e evidências. Revista de Administração de Empresas, v. 47, n. 2, p. 103-118, 2007.

FAMA, E. F.; FRENCH, K. R. The Capital Asset Pricing Model: Theory and Evidence. Journal of Economic Perspectives, v. 18, i. 3, p. 25-46, 2004.

FAMA, E. F.; MACBETH, J. D. Risk, return, and equilibrium: empirical tests. The Journal of Political Economy, v. 81, i. 3, p. 607-636, 1973.

FARIAS, T. A.; MOURA, F. R.; FIGUEIREDO, L. E. N. Capital Asset Pricing Model: um estudo de caso ao segmento da construção civil. Revista de Economia Mackenzie, v. 14, n. 2, 2018.

FERNANDES, M.; TORO, J. O Mecanismo de Transmissão Monetária na Economia Brasileira Pós-Plano Real. Revista Brasileira de Economia - RBE, v. 59, n. 1, p. 5-32, 2005.

FLETCHER, J. An Examination of the Cross-Sectional Relationship of Beta and Return: UK Evidence. Journal of Economics and Business, v. 49, p. 211-221, 1997.

FORSTER, G. Modelo de Precificação de Ativos-CAPM: Um Estudo sobre a Apuração do Custo de Oportunidade do Capital Próprio. Revista TECAP, v. 3, n. 3, 2009.

GALDI; F. C.; SECURATO, J. R. O risco idiossincrático é relevante no mercado brasileiro? Revista Brasileira de Finanças, v. 5, n. 1, p. 41-58, 2007.

GALENO, M. M. Aplicação do CAPM (Capital Asset Pricing Model) Condicional por meio de Métodos não-paramétricos para a economia brasileira: um estudo empírico do período 2002-2009. 2010. Dissertação (Mestrado em Administração)-Universidade de São Paulo, São Paulo, 2010.

HAUGEN, R. A.; BAKER, N. L. Commonality in the Determinants of Expected Stock Returns. Journal of Financial Economics, v. 41, p. 401-439, 1996.

HERRERA, F. L.; TÉLLEZ, F. J. V. Variables económicas y un modelo multifactorial para la bolsa mexicana de valores: análisis empírico sobre una muestra de activos. Academia Revista Latinoamericana de Administración, v. 29, p. 5-28, 2009. 
IBRAHIM, M. H.; AZIZ, H. Macroeconomic variables and the Malaysian equity market: a view through rolling subsamples. Journal of economic studies, v. 30, i. 1, p. 6-27, 2003.

KRISTJANPOLLER, W.; MORALES, M. Teoría de la asignación del precio por arbitraje aplicada al mercado accionario chileno. Lecturas de Economía, v. 74, p. 37-59, 2011.

LAKONISHOK, J.; SHAPIRO, A. C. Systematic risk, total risk and size as determinants of stock market returns. Journal of Banking and Finance, v. 10, i. 1, p. 115132, 1986.

LINHARES, H. da C. Análise do desempenho financeiro de investimentos ESG nos países emergentes e desenvolvidos. 2018. Trabalho de Conclusão de Curso (Graduação em Ciências Contábeis) - Universidade Nacional de Brasília, Brasília, DF, 2018.

LINTNER, J. The valuation of risk assets and the selection of risk investments in stock portfolios and capital budgets. Review of Economic and Statistics, v. 47, p. 13-37, 1965.

LIU, W. A liquidity-augmented capital asset pricing model. Journal of Financial Economics, v. 82, p. 631-671, 2006.

MACHADO, M. A. V.; MACHADO, M. R. Liquidez e precificação de ativos: evidências do mercado brasileiro. BBR-Brazilian Business Review, v. 11, n. 1, p. 7395, 2014.

MARKOWITZ, H. M. Portfolio Selection: Efficient Diversification of Investments. New York: Wiley, 1959.

MARKOWITZ, H. M. Portfolio selection. The Journal of Finance, v. 7, i. 1, p. 77-91, 1952.

MARTINSONS, M. G.; DAVISON, R. M. Strategic decision making and support systems: Comparing American, Japanese and Chinese management. Decision Support Systems, v. 43, i. 1, p. 284-300, 2007. 
MENDONÇA, M. G. de; ABRÃO, R. A. F. Subdesenvolvimento, Desindustrialização e Exploração de Recursos Naturais: o Petróleo da Camada de Pré-Sal como Chave ou Entrave para o Desenvolvimento Nacional. Revista Aurora, v. 8, n. 2, 2015.

MINISTÉRIO DA AGRICULTURA, PECUÁRIA E ABASTECIMENTO. Projeções do Agronegócio - Brasil 2012/13 a 2022/23 - Projeções de Longo Prazo. 2013. Disponível em: <http://www.agricultura.gov.br/arq_editor/projecoes\%20-\%20 versao\%20atualizada.pdf>. Acesso em: 28 ago. 2015.

MOSSIN, J. Equilibrium in a capital asset market. Econométrica, v. 34, p. 68-783, 1966.

OJALA, M.; HALLIKAS, J. Investment decision-making in supplier networks: Management of risk. International Journal of Production Economics, v. 104, i. 1, p. 201-213, 2006.

PAIVA, F. D. Modelos de precificação de ativos financeiros de fator único: um teste empírico dos modelos CAPM e D-CAPM. REGE Revista de Gestão, v. 12, n. 2, p. 49-65, 2005.

ROSS, S. A. The arbitrage theory of capital asset pricing. Journal of Economic Theory, v. 13, i. 3, p. 341-360, 1976.

ROSS, S. A.; WESTERFIELD, R. W.; JAFFE, J. F. Administração financeira. São Paulo: Atlas, 1995.

ROSTAGNO, L. M.; KLOECKNER, G. de O.; BECKER, J. L. Previsibilidade de retorno das ações na Bovespa: um teste envolvendo o modelo de fator de retorno esperado. Revista Brasileira de Finanças, v. 2, n. 2, p. 183-206, 2004.

SAMANEZ, C. P. Gestão de Investimentos e Geração de Valor. 1. ed. São Paulo: Person Prentice Hall, 2006.

SANTOS, J. O. dos; FAMÁ, R.; MUSSA, A. A Adição do Fator de Risco Momento ao Modelo de Precificação de Ativos dos Três Fatores de Fama \& French Aplicado ao Mercado Acionário Brasileiro. REGE Revista de Gestão, v. 19, n. 3, 2012.

SAUER, A.; MURPHY, A. An empirical comparison of alternative models of capital asset pricing in Germany. Journal of Banking \& Finance, v. 16, i. 1, p. 183-196, 1992. 
SCHIVINSKI, T. O Efeito da Divulgação das Demonstrações Financeiras sobre o Retorno das Ações e Avaliação do Modelo CAPM no Mercado de Capitais Brasileiro. 2002. Dissertação (Mestrado em Engenharia)-Universidade Federal de Santa Catarina, Florianópolis, 2002.

SECURATO, J. R. Decisões Financeiras em Condições de Risco. São Paulo: Atlas, 1996.

SHARPE, W. F.; ALEXANDER, G. J.; BAILEY, J. V. Investments. New Jersey: Prentice Hall, 1995.

SHARPE, W. F. Capital assets prices: a theory of Market equilibrium under condition of risk. Journal of Finance, v. 19, i. 3, p. 425-442, 1964.

SILVA, L. S. A. da; QUELHAS, O. L. G. Sustentabilidade empresarial e o impacto no custo de capital próprio das empresas de capital aberto. Gestão \& Produção, v. 13, n. 3, p. 385-395, 2006.

SILVA, W. A. M. da et al. O efeito do CAPM em relação ao retorno das ações DAS empresas listadas no novo mercado do BM\&FBovespa. Revista de Gestão, Finanças e Contabilidade, v. 7, n. 3, p. 299-313, 2017.

SILVA, W. V. da et al. Formulação de Carteiras Hipotéticas de Ativos Financeiros usando a Técnica Multivariada de Análise de Agrupamento. Revista Universo Contábil, v. 5, n. 3, p. 43-59, 2009.

SMIT, H. T. J.; TRIGEORGIS, L. Strategic investment: Real options and games. Princeton University Press, 2004.

SUN, C.; ZHANG, D. Assessing the financial performance of forestry-related investment vehicles: Capital asset pricing model vs. arbitrage pricing theory. American Journal of Agricultural Economics, p. 617-628, 2001.

TAMBOSI FILHO, E.; COSTA JÚNIOR, N. C. A.; ROSSETTO, J. R. Testando o CAPM condicional nos mercados brasileiro e norte-americano. Revista de Administração Contemporânea, v. 10, n. 4, p. 143-168, 2006.

TOBIN, J. Liquidity Preference as Behavior Towards Risk. The Review of Economic Studies, v. 25, i. 2, p. 65-86, 1958. 
TOMAZONI, T.; MENEZES, E. A. Estimativa do custo de capital em empresas brasileiras de capital fechado (sem comparáveis de capital aberto). Revista de Administração da USP, v. 37, n. 34, p. 38-48, 2002.

TREYNOR, J. L. Market Value, Time, and Risk. Unpublished manuscript. Hillsdale, Michigan: Rough Draft, 1961.

WANDERLEY, C. A. N.; SILVA, A. C. da; LEAL, R. B. Tratamento Contábil de Ativos Biológicos e Produtos Agrícolas: uma Análise das Principais Empresas do Agronegócio Brasileiro. Revista Pensar Contábil, v. 14, n. 53, p. 53-62, 2012.

\section{Como citar este artigo:}

ABNT

DAL MAGRO, Cristian Baú et al. Retorno dos investimentos de empresas do agronegócio brasileiro. RACE, Revista de Administração, Contabilidade e Economia, Joaçaba: Ed. Unoesc, v. 17, n. 2, p. 667-694, maio/ago. 2018. Disponível em: <http://editora.unoesc.edu.br/index.php/race>. Acesso em: dia/mês/ano.

APA

Dal Magro, C. B., Pamplona, E., Gorla, M. C., \& Silva, T. P. da. (2018). Retorno dos investimentos de empresas do agronegócio brasileiro. RACE, Revista de Administração, Contabilidade e Economia, 17(2), 667-694. Recuperado em dia/mês/ano, de http://editora.unoesc.edu.br/index.php/race 
